\title{
Preschoolers Self-Regulation and Their Early School Success
}

\author{
Ajeng Ayu Widiastuti \\ Early Childhood Education Program, Faculty of Education and Teacher Training \\ Satya Wacana Christian University, Salatiga, Center Java, Indonesia \\ Corresponding e-mail: ajeng.widiastuti@staff.uksw.edu
}

\begin{abstract}
This is a literature review. Self-regulation is the ability to control emotion, thought and behaviour. Self-regulation involves a process of cognitive, social and emotional. Self-regulation is more influenced by environmental factor than the temperament as individual factor. The ability of self-regulation in childhood has long-term effects and represents an important foundation for children achievement and their social life. Self-regulation involves aspects of emotional, cognitive, and social (behaviour) development. The ability to self regulates increases dramatically as children grow older. Children need to develop self-regulation skills because it has strong influence on school readiness and build relationship with peers. School readiness is defined as young children's mastery of skills that help ensure in school settings, including social emotional competence, positive attitudes toward learning, persistence, and attainment of pre academic milestones. Children cannot have the ability of self-regulation by themselves, they need adults' help. They will learn how to regulate their emotion and behaviour by watching and imitating adults. In this literature review, there are some ways can be done by adults to fostering children self-regulation in their daily life, such as find ways to say YES rather than NO; tell them what is possible rather than what is not; name emotions by using words like happy, sad, embarrassed, and proud to describe how you feel; anticipate transitions and announce changes to normal daily routines well in advance; be involved, anticipate inappropriate behaviour and re-direct it; and offer opportunities for creativity and play.
\end{abstract}

Keywords: $\quad$ self-regulation, preschoolers, school readiness, plays time

\section{INTRODUCTION}

Preschooler teachers agree that teaching 4-6 years old is like trying to keep crickets in the baskets, because another cricket jump out when we open the cover to put in a few more crickets (Bodrova \& Leong, 2008). Teachers need extra energy to manage the classroom because the crickets hard to manage their behavior and feel difficult to follow direction or classroom routines (Florez, 2011).

According to Florez (2011), preschoolers have not been able to control their emotion and behaviour. They are still in the early stages of learning to manage what they feel, think and do, and how to cope with life situations. They need adults to control and regulate themselves. Although, research suggests that children have the capacity to develop self-regulatory functions from the birth (Barkley, 1997 \& Bronson, 2000).
Self-regulation refers to self-management. According to Florez (2011) self-regulation is the ability to control emotion, thought and behavior. Self-regulation involves a process of cognitive, social (behaviour) and emotional (Blair \& Razza, 2007). Self-regulation is more influenced by environmental factor than the temperament as individual factor (Bronson, 2000).

Research suggests that self-regulation contributes to children independence development and their school achievement (Blair \& Razza, 2007). Besides, self-regulation in early years helps children to have close relationship with parents, teachers and peers (Bodrova \& Leong, 2008). However, children with fewer self regulatory skills are at greater risk for lower achievement, less social competence and more behaviour problems (Blair \& Razza, 2007). Therefore, the children need to have the ability of self-regulation. Considering this, the ability of selfregulation in childhood has long-term effects and 
represents an important foundation for children achievement and their social life.

\section{STUDIES OF SELF-REGULATION}

\subsection{Self-Regulation Development}

What is self-regulation? And how is it important? Expert have been described the self-regulation which refers to both unconscious and conscious processes that affect the ability to control responses (Carver, 2004). Self-regulation refers to several processes that allow children to appropriately respond to their environment (Bronson, 2000). Selfregulation is a deep, internal mechanism that enables children as well as adults to engage in mindful, intentional, and thoughtful behaviours (Bodrova \& Leong, 2008). Besides, according to Shonkoff \& Phillips (2000) self-regulation is a child's ability to gain control of bodily functions, manage powerful emotions, and maintain focus and attention.

The children's ability to control their behaviour is called self regulation. Gillespie \& Seibel (2006) said that self regulation can also be thought of as the successful integration of emotion (what the children feel), and cognition (what the children know) which resulting in appropriate behaviour (what the children can do). It can be conceptualized as children's own ability to manage emotions and focus attention to control behaviours to cope effectively with environmental demands, which involves aspects of emotional, cognitive, and social (behaviour) development.

\subsection{Cognitive Regulation}

According to Berk (2009), cognitive regulation is the process of continually monitoring progress toward a goal, checking outcomes, and redirecting unsuccessful efforts. Besides, cognitive regulation often called cognitive control or executive functioning, encompasses a number of cognitive factors, including working memory (the ability to mentally hold and manipulate information) and inhibitory control (the ability to resist the temptation to do something) Williford, et al (2013).

Cognitive regulation is a strong predictor of academic success (Joyner \& Kurtz in Berk, 2009). The ability to focus on and attend to an activity or task (ex. evidence good inhibitory control and attention) in preschool has been linked with higher school achievement (Blair \& Razza, 2007). Moreover, students who do well in school know whether or not their learning is going well. When they encounter obstacles, they take steps to address them, such as organize the learning environment, review confusing material, or seek support from adults or peers (Berk, 2009).

Researchers look at the impact of children's awareness of memory strategies on how well they remember, and children who can explain why a memory strategy works use it more effectively, resulting in better memory performance (Berk, 2000). Besides, children who acquire effective cognitive regulatory skills develop a sense of academic self-efficacy, confidence in their own ability, which support future use of self-regulation (Schunk \& Pajares in Berk, 2009). Thus, cognitive regulation becomes an important aspect and has a big influence on the children academic achievement and performance.

\subsection{Emotion Regulation}

The study of emotion regulation began with descriptive psychodynamic studies of defines mechanism as an individual ability to cope with stressful situations in 1960s and continue to inspire developmental studies of children's ability to selfregulate (Ochsner \& Gross, 2008).

Emotion regulation refers to the ability to inhibit negatives responses, delay gratification and control their emotional reaction to positive or negative situation (Bandy \& Moore, 2010). Thompson (1994) added that emotion regulation is the ability to manage emotional state by monitoring, evaluating, and modifying emotional reactions in ways that are constructive and adaptive.

According to Gross \& Thompson (2007), emotion process typically occurs in a four steps, which are a situation occurs that triggers an emotional response, attention is directed toward the situation, the situation is evaluated and interpreted, and an emotional response is produced.

The children, who obviously need to regulate their motions, must be able to identify and label emotions accurately, judge the emotion intensity, and identify the casual triggers. Being aware of emotional states can enable students to be more effective in their implementation of emotion regulation strategies (Smith et al, 2015). Moreover, children's emotion regulation includes both external aids (ex. comforting gestures from another) and internal strategies for managing emotional situation (Thompson \& Lagattuta, 2006). The successful of emotion regulation affect the children's functioning 
in behaviour, academic and social domains (Thompson, 1994). Considering this, emotion regulation becomes a critical state in supporting the children's social-emotional development.

\subsection{Behaviour Regulation}

Behaviour regulation is the ability to control the performance and includes compliance with adult demands and directives. It is also the ability to control impulsive responses, delay engagement in specific activities, and monitor the behaviour (Williford, et. al, 2013).

The ability to regulate the behaviour, such as sit quietly, listen the story gently or walk instead of run inside, predicts higher academic skills in the preschool year and through second grade (Mena \& Eyer, 2009). In contrast, children who are persistently behaviourally deregulated receive less instruction from teachers and have fewer opportunities to interact with peers (Ochsner \& Gross, 2008). Moreover, researchers also suggest that is there link between children's early behaviour regulation and later behavioural competence and social skills. Overall, behaviour regulation plays important role in the development of children's academic and behavioural competence.

\subsection{How does Self-Regulation Develop?}

As children grow up and their brain develops, they learn to increase self-control of both thinking and feeling (Bodrova \& Leong, 2008). It means that ability to self-regulate increases dramatically as children grow older. However, the children cannot have the ability of self-regulation by themselves, they need adults' help. They will learn how to regulate their emotion and behaviour by watching and imitating adults.

Florez (2011) stated that just like newborn babies need help regulating basic needs like body temperature, heart rate and sleeping, they also need help regulating their emotions. Babies learn to manage their emotional experiences in the simple ways, for example, looking away when the babies need a break or sucking their thumb after hearing a loud sound. Preschoolers are also learning some self-regulation skills, such as being able to wait a short time for something they want and paying attention when someone is talking with them.

Therefore, adults become role model for their children to develop self-regulation. When children see adults effectively regulate their own emotions and actions, it helps children to learn how to manage their own feelings and behaviours (Mena \& Eyer, 2009). Children learn how to regulate themselves over the time. For example, a three year old may be able to share a toy for a short time when an adult is present, but find it more difficult when an adult is away from them.

Furthermore, children are about four, they are more able to understand and manage their emotions, slow down their behaviour and focus on tasks. They also can manage two or three feelings, thoughts or tasks at the same time. In addition, children begin to exhibit more complex forms of self-regulation, such as anticipating appropriate responses and modifying their response when circumstances are subtly different. For example, clapping is more appropriate after someone speaks during sharing time at school, but not while a teacher is giving directions (Florez, 2011).

As they develop, preschoolers begin to use self-regulation skills without prompting or assistance. However, it does not mean that there is no interference or accompaniment from adults. They develop strategies to manage incoming information, choose appropriate responses, and maintain levels of arousal that allow them to actively participate in learning. When children routinely self-regulate without adults assistance, they have internalized self-regulation (Bronson, 2000). Vygotsky (1986) described internalization as a process in which children progress from co-regulating behaviour with adult to doing so independently. Thus, to develop self-regulation skills, children need many opportunities to experience and practice with adults and capable peers.

\subsection{Why is Self-Regulation Important for Preschooler?}

Children need to develop self-regulation skills because it has strong influence on school readiness and build relationship with peers. School readiness is defined as young children's mastery of skills that help ensure in school settings, including social emotional competence, positive attitudes toward learning, persistence, and attainment of pre academic milestones (ex. counting). Preschoolers already learn alongside and in collaboration with teachers and peers, and utilize their emotions to facilitate learning. Social emotional skills especially undergird their adaptation to the sometimes challenging preschool environment and subsequent successful schooling (Denham et al, 2011).

Self-regulation becomes important for preschooler because it relates to mental health 
(Florez, 2011). Preschoolers are more able to manage difficult and stressful times that occur as part of life. Besides, self-regulation skills help them to decrease the ongoing impact of stress that can contribute to mental health difficulties, such as upset, sulky, or angry. Moreover, as the children learn to self-regulate, they are also develop the skills such as concentrating, sharing, taking turns and moving from depending on others to beginning to manage by themselves. Thus, it is important to preschoolers to develop the skills of self-regulation.

\subsection{What Parents and Teacher Can Do?}

Adults can foster children self-regulation, because they learn to regulate thoughts, feelings, behaviour and emotion by watching and responding adults' self-regulation. So, adults become a role model of it. Some ways can be done by adults to fostering children self-regulation in their daily life.

According to Florez (2011) there are six ways to develop the children self-regulation, which are (1) find ways to say YES rather than NO. For example, "You can bang this pot with spoon", instead of "Don't bang on the glass table." (2) tell them what is possible rather than what is not. For example, say "Please walk" rather than "Don't run."; (3) name emotions, using words like happy, sad, embarrassed, and proud to describe how you feel; (4) anticipate transitions and announce changes to normal daily routines well in advance; (5) be involved and anticipate inappropriate behaviour and re-direct it; and (6) offer opportunities for creativity and play. Play is one of important things that can be done to develop children self-regulation considering their age are still in play time. Self-regulation occurs in child's play when they express their emotions.

Vygotsky (1978) theorized that play, specifically make-believe play, was particularly important for the development of self-regulation, as children have the opportunity to practice being regulated by, and also regulating, peers' behaviour as well as their own. Emerging research supports this theory and suggests that classroom interactions with peers during play are associated with children's self-regulation (Elias \& Berk, 2002; Mendez,

Fantuzzo \& cicchetti, 2001).

Fantuzzo, Sekino \& Cohen (2004) found that children who exhibited low levels of disruptive play behaviours had higher levels of emotion regulation, whereas disruptive and disconnected peer play behaviours were associated with negative emotional and behaviour adjustment. Also, Berk (2009) observed 3-4 years old in classrooms and found that complex sociodramatic play predicted increases on task behaviour.

\section{CONCLUSIONS}

Self-regulation is children ability to control their behaviour, which develop over time and involves many aspects of emotional, social and cognitive development. Self-regulation is also can be thought as the successful integration of emotion (what they feels) and cognition (what they know) and resulting in appropriate behaviour (what they do).

Self-regulation skills develop gradually, so it is important that adults hold appropriate expectations for children's behaviour (Florez, 2011). Adults play vital role in helping preschoolers develop foundational self-regulation skills. Providing the experiences, support, and encouragement that help preschoolers learn to self-regulate is critical element in their daily life (Shonkoff \& Phillips, 2000).

Adults can help them by showing their selfregulate from their daily life and teach the preschoolers to manage their feelings and behaviours. Adults also can foster them by doing they play. Because by playing, children express their emotions, they also develop the skills such as concentrating, sharing, taking turns and moving from depending on others to beginning to manage by themselves. These skills place children on the road to school readiness.

\section{REFERENCES}

Berkley, R.A. (1997). ADHD and the nature of selfcontrol. New York: Guilford.

Blair, C., \& Razza, R.P. (2007). Relating effortfull control, executive function, and false belief understanding to emerging math and literacy ability in kindergarten. Child Development, 78, 2, 647-663.

Bodrova, E. \& Leong, D.J. (2008). Developing selfregulation in kindergarten. Can we keep all the crickets in the basket? Beyond The Journal. Young Children in the Web. 3: 1-3.

Bronson, M.B. (2000). Self-regulation in early childhood: Nature and nurture. New York: Guilford.

Carver, C.S. (2004). Self-regulation of action and affect. In R.F. Baumeister \& K.D. Vohs (Eds.), Handbook of self-regulation: Research, theory, and applications (pp. 13-39). New York: Guilford.

Denham, et al. (2011). Factor structure of selfregulation in preschoolers: testing models of field-based assessment for predicting early 
school readiness. Manuscript accepted for publication.

Florez, I.R. (2011). Developing young children's self-regulation through everyday experiences. Young Children. Available from http://www.naeyc.org/file/yc. (accessed 18 April 2016)

Gillespie, L.G. \& Seibel, N.L. (2006). Selfregulation. A cornerstone of early childhood development. Beyond the journal. Young Children on The Web. Available from www.journal.naeyc.org/about/permissions.asp.

Shonkoff, J.D. \& Phillips, D. (2000). From neurons to neighborhoods: The science of early childhood development. A report of the National Research Council. Washington, DC: National Academies Press.

Mena, G. \& Eyer, W. (2009). Infants, Toddlers, and caregivers: A Curriculum of respectful, Reponsive Care and education ( $\left.5^{\text {th }} \mathrm{ed}\right)$, p.226, McGraw-Hill.

Ochsner, K.N. \& Gross, J.J. (2008). Cognitive emotion regulation. Insights from social cognitive and affective neuroscience. Current Direction in Psychological Science, 17, 2, 153 158.

Williford, A.P. et al. (2013). Children's engagement within the preschool classroom and their development of self-regulation. Early Education and Development, 24, 162-187. 